\title{
A Survey Study of the Usefulness and Concerns about Smart Home Applications from the Human Perspective
}

\author{
Yu Zhai', Yan Liu', Minghao Yang1, Feiyuan Long1, Johanna Virkki² \\ ${ }^{1}$ Department of Electronic Engineering, City University of Hong Kong, Hong Kong, China \\ ${ }^{2}$ Department of Electronics and Communications Engineering, Tampere University of Technology, Tampere, \\ Finland \\ Email: johanna.virkki@tut.fi
}

Received 1 October 2014; revised 1 November 2014; accepted 8 November 2014

Copyright (C) 2014 by authors and Scientific Research Publishing Inc.

This work is licensed under the Creative Commons Attribution International License (CC BY). http://creativecommons.org/licenses/by/4.0/

(c) (i) Open Access

\begin{abstract}
It is not yet clear how smart home technologies and applications will actually be accepted as part of our everyday lives. In this research, the thoughts of 248 people about smart homes were collected by interviews and with an Internet survey in Europe and Asia. It was found that people have very versatile thoughts about what the term "smart home" means in practice and when smart houses will become part of our daily lives. The Asian answerers can be considered to be slightly more optimistic about the schedule. The majority of the answerers were found to be interested in versatile smart home applications and willing to live in a smart house. The cost can be considered to be their biggest worry and the Asian answerers were found to be more worried about the reliability, practicability, and cost than the answerers from Europe. Also some privacy concerns were found from both the European and the Asian answerers.
\end{abstract}

\section{Keywords}

Asia, Europe, Internet Survey, Interviews, Personal Perspectives, Smart Homes

\section{Introduction}

The growth of the Internet of Things (IOT) means more and more daily things and devices connecting each other and creating a pervasive computing world where they will exchange data and information about the environment, while reacting independently to different events, influencing their surroundings, and creating services with or without human intervention. The IOT has potential applications in all areas of life [1] [2]. Despite the 
fast development of versatile applications, it is not yet clear which of these will actually be accepted as a part of our daily lives. For example, in a study made in Finland, the IOT and its applications were seen tempting, in principle, but the necessity of the versatile applications was also questioned by the answerers [3]. During the last two decades, user acceptance models to reflect people's willingness to accept new technologies, e.g., smart products [4], have been developed, tested, refined, extended, and unified. For example, in a study from China, the authors proposed an IOT acceptance model consisting of several factors: the results showed particularly strong support for the effects of perceived usefulness, ease of use, enjoyment, and behavioral control, and also of social influence [5]. Also the results of another study showed that the acceptance of IOT services would be affected by various contradicting factors, such as perceived privacy risks and personal interests. It was also assumed that legislation, data security and transparency of information influence the adaptation [6]. In a yet another study, made in China, it was found that usefulness plays an important role in acceptance of the IOT [7].

One of the most important IOT application areas are smart houses [8]. Smart home, comprising smart devices and things in the home context, promises enormous possibilities to our future life, e.g., by automation of the home, housework, or household activities. At the same time, smart homes will probably have their own influence to change our living habits. Moreover, as home is not just a physical house for people [9], in addition to technology development, the needs and thoughts of future smart home inhabitants also need to be studied. For example, a survey focusing on the activities and habits that people do at home that they would not want to be recorded has been conducted, and bedroom has been found to be the most private place [10]. One of the most important challenges in convincing users to adopt this kind of all-around network in their home is the protection of privacy. Concerns over privacy can spread wide, particularly as these wireless systems can track users' actions, behaviour and ongoing preferences. Possible privacy problems, however, are not caused by the technology alone, but primary through activities of people, businesses, and the government [6] [11]. One study exploring the social barriers to smart home diffusion, including how these vary by expertise, life-stage, and location, highlighted the importance of control, security, and cost [12]. The results of another study, analyzing the attitudes of users towards different types of ambient assisted living services, showed that users were not yet (in 2011) very familiar with the vision of smart technology at home and reported hesitancy and aloofness towards using such technologies. Persons with many social contacts and a high interest in technology showed the highest acceptance for electronic services at home. The results for the different applications were insensitive to gender and age [13]. One major reason for the unenthusiastic acceptance might be the fact that current developments in this sector are in many parts focusing on technical feasibility, inspired by technical disciplines, leaving the human factor in these systems fairly under developed. However, at least at the current maturity of technical solutions, the human perspective should be incorporated into technical designs as soon as possible [14].

The personal thoughts and feelings of people who are potential end users of the IOT and its applications, i.e., "ordinary people", are an important research area. In this research, the thoughts of 248 people from Europe and Asia were collected by interviews and with an Internet survey. The main focus was to find answers to the following questions:

1) Are the answerers already familiar with smart houses and smart home applications?

2) Do the answerers feel that smart home applications would be useful in their lives?

3) Are there any privacy concerns or concerns about the practicability, cost, or reliability of the technology used in these applications?

This paper is organized as follows: The introduction section introduces the topic and the goals of this study. Section 2 presents the performed interviews and the Internet survey, including the information on the answerers and the presented questions. The collected answers and examples from free comments are presented and discussed in Section 3. The last section summarizes the results and presents the conclusions of this paper.

\section{Interviews and Internet Survey}

All the data for this research was collected during June-August 2014. In the first part of this research, 95 people were interviewed and Table 1 shows more information about the answerers. People of different age, of both gender and of different occupation were chosen from Europe (50 people, all of them from Finland) and from Asia (45 people, all of them from Hong Kong and mainland China). Personal interviews took place either at the answerers working facility or at a neutral, public place. Some of the interviews were done by private e-mails between the researcher and the answerer. All these interviews thus had more flexibility than an anonymous paper 
Table 1. The answerers of this study.

\begin{tabular}{cccccccc}
\hline & & \multicolumn{3}{c}{ Internet survey } & \multicolumn{3}{c}{ Interviews } \\
\cline { 3 - 8 } & & Asian & European & All & Asian & European & All \\
\hline \multirow{3}{*}{ All } & & 103 & 50 & 153 & 45 & 50 & 95 \\
& Male & 50 & 26 & 76 & 25 & 29 & 54 \\
& Fender & 53 & 24 & 77 & 20 & 21 & 41 \\
& $18-25$ & 74 & 18 & 92 & 30 & 23 & 53 \\
& $26-35$ & 20 & 25 & 45 & 15 & 13 & 28 \\
& $36-45$ & 3 & 4 & 7 & 0 & 6 & 6 \\
& $46-55$ & 6 & 1 & 7 & 0 & 6 & 2 \\
\hline
\end{tabular}

or Internet survey, as both the researcher and the answerer were able to ask for clarification. However, personal interviews are quite time-consuming and thus also a more effective method to gather data was needed.

The second part of this study was an Internet survey, where 153 answers were collected, again from people of different age, of both gender, and of different occupation (also shown in Table 1). There were 50 people from Europe (from Finland, Sweden, Portugal, Germany, Italy, Bulgaria, Norway, Russia, Slovenia, United Kingdom, Spain, and France) and 103 from Asia (from mainland China, Hong Kong, Iran, India, Korea, and Afghanistan).

The interviews consisted of the following questions:

1a) Have you heard about smart homes before? (Yes/No)

1b) What have you heard about them? What do you know about smart homes?

1c) Would you be willing to live in a smart home? (Yes/No)

2) What kind of smart home applications are you or your friends/family interested in? (Including a list of applications)

3) What are your major worries about smart homes, if any? (Including a list of possible worries)

4) When do you think smart homes will become a part of our everyday life?

The Internet survey covers all the questions from the interviews and the following extra question:

5a) Would you allow your smart home to record people's personal information when they enter the house? (Yes/No)

5b) Would you allow your smart home to record your movement around the house? (Yes/No)

5c) Would you allow your smart home to record your house health status? (Yes/No)

5d) Would you allow your smart home to record your personal health status? (Yes/No)

Also: How worried would you be about your individual privacy in above situations 5(a) - 5(d)? (Scale: 1 - 5; $1=$ not worried at all, 5 = very worried).

\section{Results and Discussion}

This section introduces and discusses the collected answers. All the examples of the achieved free comments are presented as direct quotes and their text is italicized.

As can be seen from Table 2, 76\% of the Asian and 64\% of the European answerers in the interviews were familiar with smart homes. The percentages were 74\% (Asian) and 88\% (European) in the Internet survey. There is a significant difference between the results from the interviews and the Internet survey in the case of the European answerers. This can be partly explained by the fact that all of the answerers in the interviews were from Finland, whereas in the Internet survey there were answerers from several European countries. Thus, one limitation in the use of the interview results of this study is that people from Finland and China are not representative enough to reflect the attitudes of European people and Asian people, respectively. However, also the fact that the answerers of the Internet survey probably are more familiar with new technologies in general may have affected the results. The percentages of Asian answerers were similar in the interviews and in the Internet survey also with question 1(c), where 82\% (interviews) and 86\% (Internet survey) of the Asian answerers were 
Table 2. Answers to questions 1(a) and 1(c) about smart homes.

\begin{tabular}{|c|c|c|}
\hline \multicolumn{3}{|c|}{ 1(a). Have you heard about smart homes before? } \\
\hline \multicolumn{3}{|c|}{ Interviews } \\
\hline & Asian & European \\
\hline Yes & $76 \%$ & $64 \%$ \\
\hline No & $24 \%$ & $36 \%$ \\
\hline \multicolumn{3}{|c|}{ Internet survey } \\
\hline & Asian & European \\
\hline Yes & $74 \%$ & $88 \%$ \\
\hline No & $26 \%$ & $12 \%$ \\
\hline \multicolumn{3}{|c|}{ 1(c). Would you be willing to live in a smart home? } \\
\hline \multicolumn{3}{|c|}{ Interviews } \\
\hline & Asian & European \\
\hline Yes & $82 \%$ & $74 \%$ \\
\hline No & $18 \%$ & $26 \%$ \\
\hline \multicolumn{3}{|c|}{ Internet survey } \\
\hline & Asian & European \\
\hline Yes & $86 \%$ & $92 \%$ \\
\hline No & $14 \%$ & $8 \%$ \\
\hline
\end{tabular}

willing to live in a smart home. Again, there was a difference in the answers from Europe: $74 \%$ (interviews) and 92\% (Internet survey) were willing to live in a smart home. However, according to these results, in all cases, the majority of the answerers were willing to live in a smart home.

Following quotes are examples of the versatile comments about what people have heard or what they know about smart homes: "App to control everything; automatic AC, lights, heating; sound control for the lights; refrigerators can order food automatically; automatically monitor electricity usage; lock home and alarm system; wireless detector to detect who is in your home; iPad can control the home applications; solar energy roof; home appliances are connected by the wireless network; automatically tell you what is turned on/off by phone".

Automatic heating and lightning control were the most often mentioned applications and also automatic fridge was mentioned several times. Some of the answerers from Finland mentioned smart or automatic sauna. In free comments, it was stated that modern houses already can have smart hardware installed and thus it should be easy to implement a smart home. However, it was also commented that integration of such smart applications to existing houses may be difficult and expensive. In some comments, the whole concept was questioned and it was, e.g., stated that smart homes are "only things seen in the movies". Many people also commented that although they have heard about smart homes, they do not actually know what the smart homes will be like in real life and what they can expect and demand from the future smart applications at home. Thus, also the results of the acceptance of the whole smart home concept in this study have to be seen as acceptance of what the answerers think the future smart homes will be like and what applications they think smart homes will include.

The smart home applications in this study were chosen to be from versatile areas of everyday life. In Table 3 , it is presented what kind of smart home applications the answerers were interested in. Many people chose more than one application and all of the applications gained some interest. However, in free comments it was, e.g., stated that people are "living just fine without these new applications". These comments are in line with the earlier mentioned results achieved in [3]. As can be seen, a single application cannot be named to be the most 
popular, although, e.g., temperature \& humidity control and smart cleaning can be considered to be interesting ones among all answerers. In the future, it is important to study the opinions and interests of people application by application and also empirical user studies can be valuable. For example, in one study, a simulation of a smart fridge was developed and the people's opinions on smart fridge offering different assistance functions were studied [15]. In our study, the Asian answerers were more interested in different smart home applications than the answerers from Europe. It was also noticed that the European Internet survey answerers were not particularly interested in any of the applications, compared to all other answerers. It is surprising, since $92 \%$ of them answered that they would like to live in a smart home.

The answers to question about the major worries related to smart homes can be seen in Table 4. In general, the Asian people were more worried than the people from Europe; the percentages are higher in all options (individual privacy, reliability of technology, practicability, and cost) and the same result was achieved both in the Internet survey and in the interviews. Also in a previous study about versatile IOT applications, the answerers from Finland were less worried about the individual privacy in the IOT than the answerers from China [16]. Among the Asian answerers, cost can be named as the biggest worry, although also other percentages were quite high. In the European interviews (people from Finland), cost was clearly the main worry. However, among the European answerers of the Internet survey, there is no single major worry.

Table 3. Answers to question 2 about smart homes.

\begin{tabular}{ccccc}
\hline \multicolumn{2}{c}{ 2. What kind of smart home applications are you or your friends/family interested in? } \\
\hline \multicolumn{2}{c}{ Interviews } & \multicolumn{3}{c}{ Internet survey } \\
\hline & Asian & European & Asian & European \\
\hline Security control & $56 \%$ & $40 \%$ & $44 \%$ & $14 \%$ \\
Temperature \& humidity control & $49 \%$ & $52 \%$ & $65 \%$ & $11 \%$ \\
Smart lighting & $51 \%$ & $36 \%$ & $69 \%$ & $10 \%$ \\
Home entertainment system & $38 \%$ & $26 \%$ & $57 \%$ & $11 \%$ \\
Yard management system & $31 \%$ & $14 \%$ & $39 \%$ & $4 \%$ \\
Smart cleaning & $53 \%$ & $50 \%$ & $75 \%$ & $11 \%$ \\
Senior nursing system & $53 \%$ & $26 \%$ & $60 \%$ & $7 \%$ \\
Childcare system & $42 \%$ & $20 \%$ & $74 \%$ & $7 \%$ \\
Disabled nursing system & $40 \%$ & $12 \%$ & $29 \%$ & $2 \%$ \\
Energy management system & $47 \%$ & $40 \%$ & $69 \%$ & $11 \%$ \\
Window \& curtain control system & $22 \%$ & $18 \%$ & $56 \%$ & $8 \%$ \\
Pets feeding system & $7 \%$ & $16 \%$ & $33 \%$ & $5 \%$ \\
\hline
\end{tabular}

Table 4. Answers to question 3 about smart homes.

\begin{tabular}{ccccc}
\hline \multicolumn{3}{c}{ 3. What are your major worries about smart homes, if any? } \\
& \multicolumn{2}{c}{ Interviews } & \multicolumn{2}{c}{ Internet survey } \\
\cline { 2 - 4 } & Asian & European & Asian & European \\
\hline Yourindividualprivacy & $56 \%$ & $38 \%$ & $37 \%$ & $30 \%$ \\
Reliability of technology & $49 \%$ & $28 \%$ & $55 \%$ & $27 \%$ \\
Practicability & $53 \%$ & $6 \%$ & $53 \%$ & $15 \%$ \\
Cost & $62 \%$ & $54 \%$ & $61 \%$ & $26 \%$ \\
Other & $2 \%$ & $2 \%$ & $2 \%$ & $2 \%$ \\
\hline
\end{tabular}


As can be seen from Table 5, people have very different thoughts about the possible schedule of smart homes coming to everyday use. For example, in the Internet survey, $42 \%$ of the answerers thought it would happen during following 5 - 10 years and $29 \%$ of the Asian and 38\% of the European answerers felt that it will take 11 20 years. In addition, $21 \%$ of the Asian and $8 \%$ of the European felt it will happen in the near future. In general, the Asian answerers can be considered to be slightly more optimistic about the schedule. None of the answerers felt that this would never happen. Similar major dispersion was also found in the answers of the interviews, also shown in Table 5. One major reason for these differences may be the found fact that people have very different thoughts about what is meant by smart homes coming to everyday life and even what is meant by smart home. However, this diversity of results is also in line with the diversity of the results of another study (published 2013), where it was inquired what the answerers think will be the possible schedule for the current Internet to grow into the IOT and this kind of all-around network to come to use [16].

The privacy concerns of future smart technology users are an important research area. For example, in one study, the reputation of the retailer and acceptance of RFID-based information services was investigated. Results showed that people are moderately privacy aware and that their privacy awareness is negatively related to their acceptance of the service. Also, a group of "extreme rejecters" that hold highly negative attitudes and significantly bias group means were found [17]. Also in our study, when the answerers were asked to give a number for their amount of worry about their individual privacy in different scenarios, the whole scale from 1 to 5 was used by the answerers. For our study, we chose 4 different scenarios (5(a) - 5(d)) and chose to present the average number of worry for each group (see Table 6). In an earlier study about people's worries related to their individual privacy, among different IOT applications, the applications related to personal health were considered the least worrying ones and the applications related to personal finances were found to be the most worrying ones [16].

It can be seen from Table 6 that about half of all the Asian answerers and 32\% of the European answerers would allow a smart home to record people's personal information when they enter the house. The average number of worry in this situation was 3.55 for the Asian and 3.72 for the European answerers. Only 31\% of the Asian would allow the house to record their movement around the house, whereas the percentage for European answerers was $60 \%$. There was also a difference in the average value of worry in this question; the average value of worry (between 1 - 5) was 3.65 for the Asian and 3.14 for the European answerers. Almost all of the answerers would allow their smart home to record the house health status and the average numbers of worry were also quite low in this case for both Asian and European answerers; 2.35 and 2.22, respectively. Also, 83\% of the Asian and $78 \%$ of the European answerers would allow their own personal health status to be monitored by their house. The average number of worry for Asian and European answerers was 2.79 and 3.18, respectively. Thus, people were quite willing to let their smart home to record information about their own health and the health of the house but not so willing to let people's personal information or their movement around the house to be recorded.

\section{Conclusions}

The personal thoughts and feelings of people who are potential end users of the IOT and its applications, i.e., "ordinary people" offer important information for people working to develop the IOT and its applications, e.g.,

Table 5. Answers to question 4 about smart homes.

\begin{tabular}{|ccccc}
\hline \multicolumn{2}{|c}{ 4. When do you think smart homes will become a part of our everyday life? } \\
\hline \multicolumn{2}{c}{ Interviews } & & \multicolumn{2}{c}{ Internet survey } \\
\hline & Asian & European & Asian & European \\
\hline In the near future & $24 \%$ & $18 \%$ & $21 \%$ & $8 \%$ \\
During 5 - 10 years & $36 \%$ & $26 \%$ & $42 \%$ & $42 \%$ \\
During 11 - 20 years & $29 \%$ & $36 \%$ & $29 \%$ & $38 \%$ \\
Morethan 20 years & $11 \%$ & $20 \%$ & $8 \%$ & $12 \%$ \\
Never & $0 \%$ & $0 \%$ & $0 \%$ & $0 \%$ \\
\hline
\end{tabular}


Table 6. Answers to question 5 about smart homes.

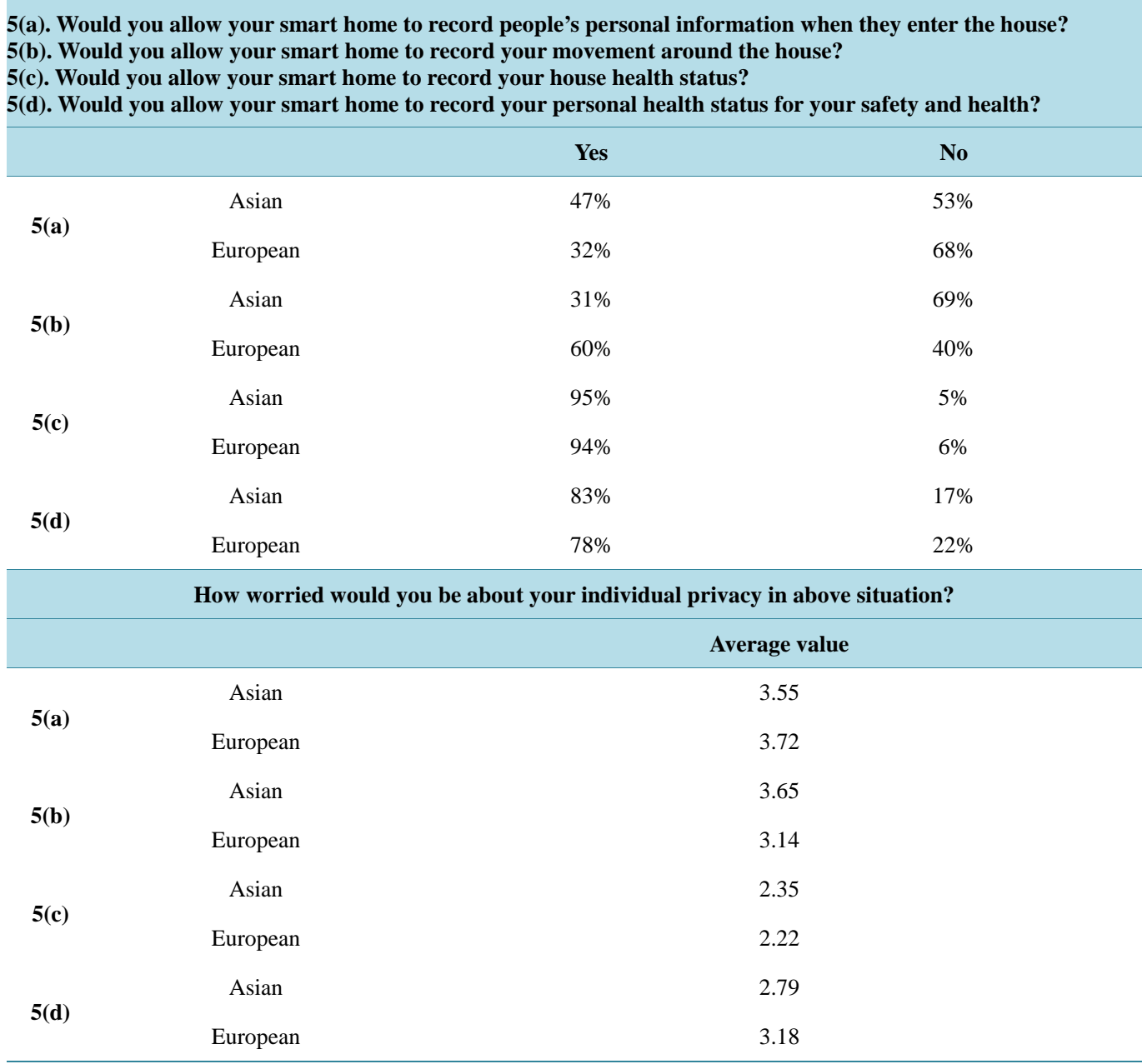

smart home applications. In this research, the thoughts of people about different aspects of smart homes were collected. It was found that majority of the answerers were somehow familiar with smart homes and also willing to live in a smart house. However, people were found to have different thoughts about what is actually meant by smart homes and they also had different thoughts about the possible schedule of smart homes coming to everyday use. The Asian answerers can be considered to be slightly more optimistic about the schedule than the answerers from Europe. People were found to be interested in versatile smart home applications and cost can be considered to be the biggest worry. In general, the Asian people were more worried about the reliability, practicability, and cost than the people from Europe. Also some concerns about the individual privacy were found both from Europe and Asia, related to a smart home recording the habits, movement, and information of the inhabitants. In future research, it is also important to study the smart home environment application by application, not just the whole wide concept.

\section{Acknowledgements}

This research was supported by Helsingin Sanomat Foundation. The authors would also like to thank the City University of Hong Kong Overseas Internship Scheme 2014.

\section{References}

[1] Libelium (2012) 50 Internet of Things Applications. http://www.libelium.com/top_50_iot_sensor_applications_ranking

[2] Guo, B., Zhang, D. and Wang, Z. (2011) Living with Internet of Things: The Emergence of Embedded Intelligence. 
Internet of Things (iThings/CPSCom).

[3] Virkki, J. (2013) Finnish Perspectives for the IOT. American Journal of Networks and Communications, 2, 23-27.

[4] Mayer, P., Volland, D., Thiesse, F. and Fleisch, E. (2011) User Acceptance of “Smart Products”: An Empirical Investigation. Wirtschaftsinformatik Proceedings, Paper 9.

[5] Gao, L.L. and Bai, X.S. (2014) A Unified Perspective on the Factors Influencing Consumer Acceptance of Internet of Things Technology. Asia Pacific Journal of Marketing and Logistics, 26, 211-231. http://dx.doi.org/10.1108/APJML-06-2013-0061

[6] Kowatsch, T. and Maass, W. (2012) Privacy Concerns and Acceptance of IoT Services. The Internet of Things 2012New Horizons, IERC Cluster Book, Halifax.

[7] Wang, H., Yan, Y., Hu, Z. and Zhang, Y. (2011) Consumer Acceptance of IOT Technologies in China: An Exploratory Study. International Conference on Technology Education (ICTE), Chengdu, 23-25 July 2011, 2430-2435.

[8] Aldrich, F. (2003) Smart Homes: Past, Present and Future, In: Harper, R., Ed., Inside the Smart Home, Springer Verlag, Berlin, 17-36. http://dx.doi.org/10.1007/1-85233-854-7_2

[9] Saizmaa, T. and Hee-Cheol, K. (2008) Smart Home Design: Home or House? International Conference on Convergence and Hybrid Information Technology, Busan, 11-13 November 2008, 143-148.

[10] Choe, E.K., Consolvo, S., Jung, J., Harrison, B. and Kientz, J.A. (2011) Living in a Glass House: A Survey of Private Moments in the Home. In: Proceedings of the 13th International Conference on Ubiquitous Computing, ACM, New York, 41-44.

[11] Solove, D.J. (2006) A Taxonomy of Privacy. University of Pennsylvania Law Review, 154, Paper No. 129.

[12] Balta-Ozkan, N., Davidson, R., Bicket, M. and Whitmarsh, L. (2013) Social Barriers to the Adoption of Smart Homes. Energy Policy, 63, 363-374. http://dx.doi.org/10.1016/j.enpol.2013.08.043

[13] Ziefle, M., Rocker, C. and Holzinger, A. (2011) Perceived Usefulness of Assistive Technologies and Electronic Services for Ambient Assisted Living. Proceedings of the 5th International ICST Conference on Pervasive Computing Technologies, Dublin, 23-26 May 2011, CD-ROM.

[14] Gaul, S. and Ziefle, M. (2009) Smart Home Technologies: Insights into Generation-Specific Acceptance Motives, HCI and Usability for e-Inclusion. Lecture Notes in Computer Science, 5889, 312-332. http://dx.doi.org/10.1007/978-3-642-10308-7_22

[15] Rothensee, M. (2008) User Acceptance of the Intelligent Fridge: Empirical Results from a Simulation. The Internet of Things. Lecture Notes in Computer Science, 4952, 123-139. http://dx.doi.org/10.1007/978-3-540-78731-0_8

[16] Virkki, J. and Chen, L. (2013) Personal Perspectives: Individual Privacy in the IOT. Advances in Internet of Things, 3, 21-26. http://dx.doi.org/10.4236/ait.2013.32003

[17] Rothensee, M. and Spiekermann, S. (2008) Between Extreme Rejection and Cautious Acceptance, Consumers’ Reactions to RFID-Based IS in Retail. Social Science Computer Review, 26, 75-86. 
Scientific Research Publishing (SCIRP) is one of the largest Open Access journal publishers. It is currently publishing more than 200 open access, online, peer-reviewed journals covering a wide range of academic disciplines. SCIRP serves the worldwide academic communities and contributes to the progress and application of science with its publication.

Other selected journals from SCIRP are listed as below. Submit your manuscript to us via either submit@scirp.org or Online Submission Portal.
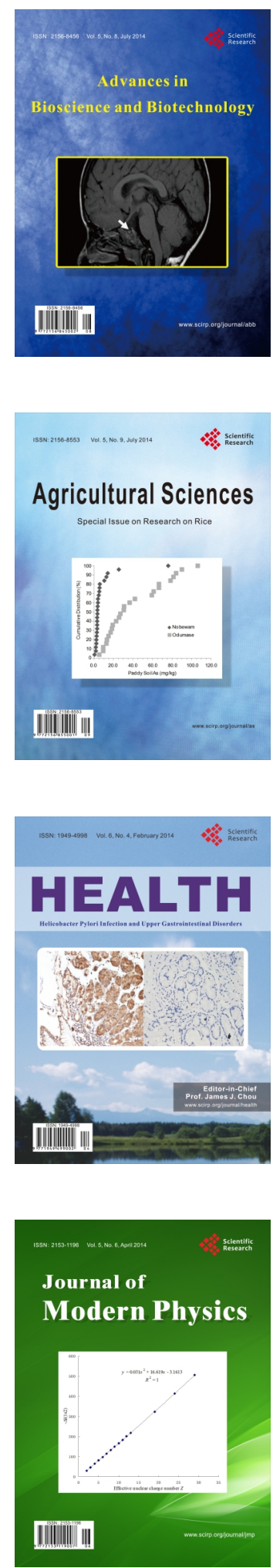
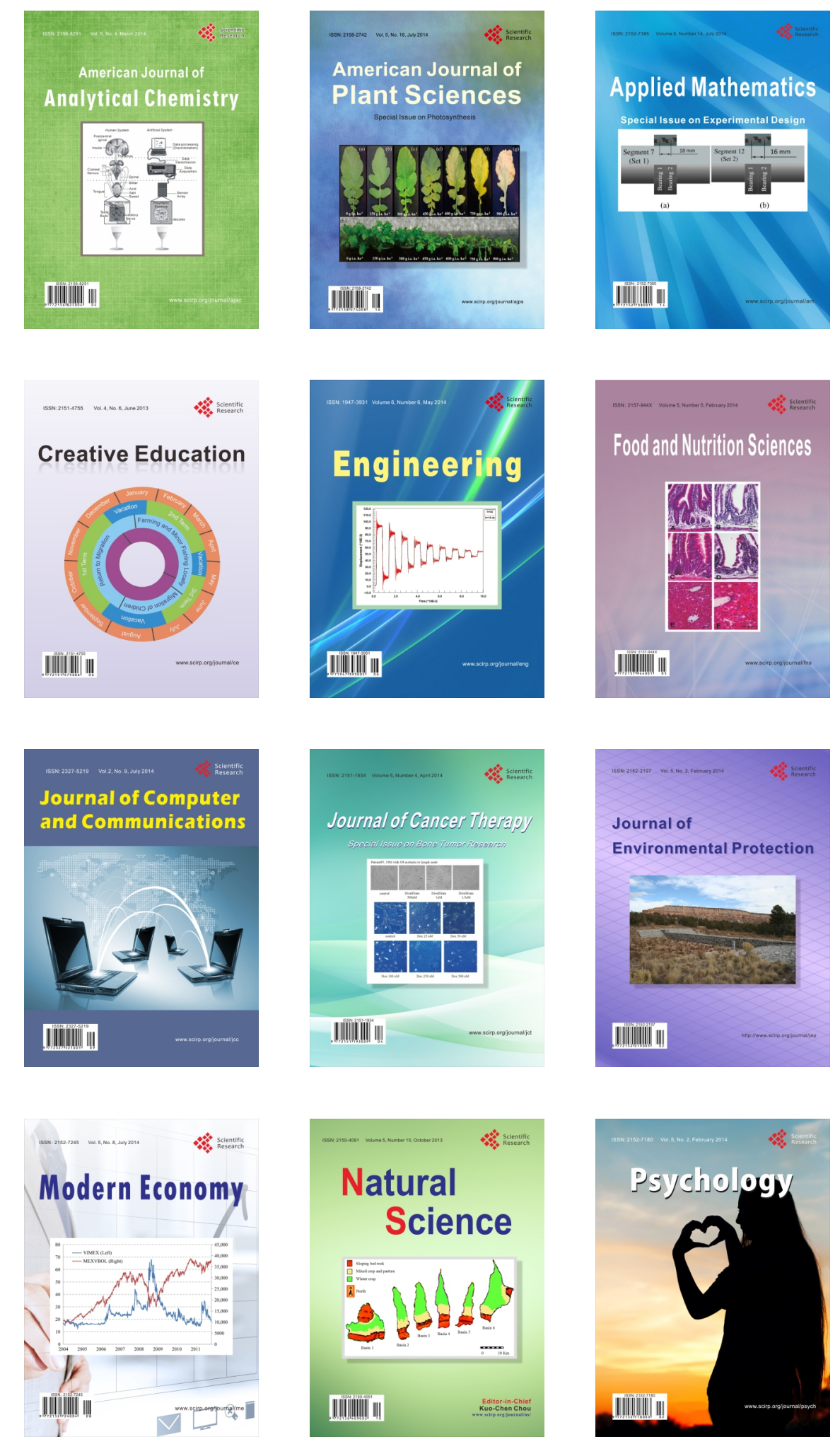